\section{Mnemonic innagery and forgetting}

\author{
LOWELL D. GRONINGER* \\ University of Maryland, Baltimore County, Baltimore, Md. 21228
}

A group in which Ss learned a 25-word list of high-imagery words with a mnemonic imagery technique (method of loci) was compared to a control group who basically learned the list by grouping the words. All Ss were required to learn the words in a given order. Learning times, along with three types of recall measures involving ordering of words and a recognition memory measure, were taken after 1 and 5 weeks. The results showed that learning was faster and recall better with fewer order errors in the imagery condition. The recognition memory measure showed very high scores in both groups, with no significant differences between them. The results were interpreted as showing that at least part of the effectiveness of mnemonic imagery devices comes about by making items more accessible during recall.

Recent studies (see Paivio, 1969) have shown that mnemonic devices using imagery facilitate the acquisition of concrete words in various situations. However, little attention has been given to the relationship between these imagery techniques and specific problems involving retention and retrieval after long time durations. Of particular relevance to recall after long time periods are questions involving trace availability and trace accessibility. Studies demonstrating "tip of the tongue" behavior (Brown \& McNeill, 1966) and "feeling of knowing" (Hart, 1965) show that a response item is frequently available but, at least temporarily, not accessible.

Research from a number of different perspectives leads to some interesting speculations involving the concepts of trace availability and trace accessibility in relation to mnemonic imagery devices. Shepard (1967) and Standing, Conezio, \& Haeber (1970) have shown that recognition memory for pictures is phenomenally high. For example, Standing et al (1970) presented 2,560 magazine pictures at 5 - and 10-sec rates and found that $S$ could recognize correctly about 95\% on a test sample. Paivio (1969) has reviewed evidence showing the superiority of pictures over words as measured by recognition and has suggested that visual images are functionally related to visual perception. Thus, one possible explanation for increased recall after long retention intervals with the use of mnemonic imagery systems is that they increase the strength of a memory trace by tapping into a very powerful perceptual memory system,

*The author would like to thank Bernie Wess for his assistance in collecting the data. Requests for reprints should be sent to Lowell Groninger, Department of Psychology, University of Maryland, Baltimore County, Baltimore, Maryland 21228. and this would make the trace available over a longer time duration. Another explanation of the effectiveness of imagery systems, is that they may facilitate the retrieval of memory traces by providing cues to the traces which would make them more accessible. For example, using the "one is a bun" technique (Miller, Galanter, \& Pribram, 1960), the function of the cue or "peg" words may be to mediate a compound image involving the required response. Thus, the function of the image mediator would be to aid in the retrieval process. It should be pointed out that neither of these possibilities is mutually exclusive, and the effectiveness of mnemonic imagery systems may be a function of both these suggestions, and perhaps more.

In addition to the availability vs accessibility question, there is also the matter of the correct ordering of a number of items. Most mnemonic devices using imagery incorporate order in their systems. For example, in the "method of loci" technique described by Yates (1966), the cue images have a predetermined order which should considerably reduce and possibly eliminate order errors in their recall. It would, therefore, be expected that if the cue images were being used in the recall of a set of items, the items themselves would also show few order errors.

In attempting to gather information on the questions concerning imagery techniques, the method of loci was used in this study. This method has the particular advantage of allowing large numbers of cue images to be ordered, whereas the effective limit of cue images with the "one is a bun" technique is 10 . In testing for differences between trace availability and accessibility, recognition memory was assumed to be a measure of trace availability, since it does not involve retrieval problems, while unaided recall was assumed to be a measure of both trace availability and accessibility. Differences between the measures would then reflect the extent to which traces were available but not accessible.

The Ss were students at the University of Maryland, Baltimore County, who served in this study as a substitute for other course work.

\section{MATERIALS}

The words used in this experiment were high in imagery, as determined from the norms of Paivio, Yuille, \& Madigan (1968), with ratings of not less than 6.4 on a 7.0 scale. Twenty-five words were chosen in haphazard fashion from this group, with an attempt made to avoid obviously highly associated word groups. The words were typed separately on $3 \times 5$ in. cards, shuffled, then numbered at the top of each card, the numbers representing the order of the cards in the deck. Six decks representing six orders of words were constructed in this fashion.

\section{PROCEDURE}

The general design of the experiment was to equate learning under an imagery condition (method of loci) and a control condition, and to measure forgetting using recall and recognition memory tasks after 1 and 5 weeks. Ss were given instructions in groups up to six in number and then sent into individual enclosed booths to perform the task. The imagery group was told about the usage of imagery in learning and that they were to go into the booths and think of 25 locations that could be easily ordered, such as locations that were familiar along a common drive or walk. The $\mathrm{Ss}$ were instructed to take as much time as they needed and, when they were finished, to come to the $E$, who would then give them words to learn by mentally picturing them in the locations. Ss were not timed during this phase but generally took about $10 \mathrm{~min}$. When a $\mathrm{S}$ was ready for a deck of words to learn, he was given an example of the use of the method of loci and told to learn all 25 words in order, using this technique; when he was confident that he could recall all 25 , he was to come to the $E$ and write, in order, the words with their corresponding mnemonic locations. The decks were distributed so that all six orders of words were used an equal number of times.

The control group was simply told to go into the booths and learn the 25 words in order by whatever means they chose. Both groups were told that learning time was of interest to the $E$ and that the length of time that it took them to learn the list would be recorded. Learning time was measured from the time each $S$ entered a booth with the 25 words until he left the 
Table 1

Mean Learning Times and Number of Words Correctly Recalled from the 25-Word List After 1 and 5 Weeks

\begin{tabular}{|c|c|c|c|c|c|}
\hline Condition & LT & CLP & COP & TLR & CR \\
\hline $\begin{array}{l}\text { Imagery } \\
\text { Control }\end{array}$ & $\begin{array}{l}13 \mathrm{Min} 49 \mathrm{Sec} \\
17 \mathrm{Min} 11 \mathrm{Sec} \\
\mathrm{p}<.025\end{array}$ & $\begin{array}{l}23.26 \\
15.92 \\
p<.001\end{array}$ & $\begin{array}{l}\quad 1-\text { Week } \\
23.42 \\
17.30 \\
p<.005\end{array}$ & $\begin{array}{l}\text { Recall } \\
23.57 \\
20.44 \\
\text { p }<.005\end{array}$ & $\begin{array}{l}24.75 \\
24.56 \\
p>.05\end{array}$ \\
\hline $\begin{array}{l}\text { Imagery } \\
\text { Control }\end{array}$ & & $\begin{array}{c}19.87 \\
9.43 \\
p<.001\end{array}$ & $\begin{array}{l}\quad \text { 5-Week } \\
21.13 \\
12.39 \\
\text { p }<.001\end{array}$ & $\begin{array}{l}\text { Recall } \\
22.67 \\
18.26 \\
p<.01\end{array}$ & $\begin{array}{l}24.13 \\
23.83 \\
\text { p > .05 }\end{array}$ \\
\hline
\end{tabular}

booth to write the words. Following the writing of the word list, the Ss were given. questionnaires inquiring about the techniques that they actually employed in learning the list. The Ss were then asked to return the following week and instructed not to rehearse the list, or imagery technique in the case of the experimental group, in the meantime.

During the recall period following the 1-week retention interval, the Ss were first asked to try to write in order all of the words from the list that they could remember. In addition, the imagery group was asked to. write short descriptions of the images of locations that they used in learning the list. Ss were given all the time they wished in attempting to recall the items and were encouraged not to give up too easily. After they finished their recall, they were given a recognition memory task with the 25 correct words randomly interspersed with 25 distractor words chosen from the same level of imagery in the Paivio et al (1968) norms. A questionnaire inquiring about rehearsal of the items during the retention interval then followed. The same procedure was used during the test after a 5-week retention, except that the Ss were not notified of this test until the preceding day.

\section{RESULTS}

A primary methodological concern in studies incorporating long retention intervals is the possibility of rehearsal during this period. This is of particular concern in the present study, since students usually find imagery techniques novel and interesting; this might result in rehearsal of the items or the use of the technique in learning additional lists of words. It was felt that the best solution to this problem, as well as the problem of the precise method actually employed in learning the lists, was to ask the Ss for frank and honest answers regarding these matters (Orne, 1962). From these answers, Ss were discarded if they reported rehearsing the list at any time or times other than immediately after writing out the list after initially learning it or immediately before a subsequent later recall session.
There were initially $36 \mathrm{Ss}$ in the control group who wrote out all 25 items in order. Six of these were discarded for rehearsing, three failed to return after 1 week, and four more failed to return after 5 weeks, making a total $N$ of 27 after 1 week and 23 after 5 weeks. The corresponding decrement for the experimental group from a start of 36 was $6,5,4$. In addition, six Ss were discarded when their questionnaires showed that they had not used imagery as the primary means of learning the list. The final numbers for the imagery group was 19 after 1 week and 15 after 5 weeks. In discarding data based on the questionnaires, the responses were first separated from the questionnaire so that independent judging of the questionnaires could be obtained.

Although the $\mathrm{Ss}$ in the control group were given freedom in the method in which they chose to learn the list, 24 of the 27 learned the list by rehearsing them in groups ranging in sizes from two to five, with five being used by 20 of 27 Ss. Thus, the majority of the control Ss learned the items by grouping, even though the order requirement probably prevented the use of subjective categories of the type described by Mandler (1967).

The measures given in Table 1 are: learning time (LT); correct by list position (CLP), where an item had to be recalled in the same position in the list as it was presented to be scored correct; correct by ordinal position (COP), where an item was scored as correct if it occurred either in its correct list position or if it occurred in its correct ordinal position relative to the preceding or following word; total list responses (TLR), a count of the total responses given from the list irrespective of order; correct by recognition (CR), where items from the list were interspersed with 25 additional items with the $S$ required to check the list items. Statistical tests between imagery and control groups within each measure showed significance at or beyond the .025 level for all comparisons except for the CR measures, which were not significant at the .05 level. In addition, $t$ tests were performed on the number of order errors between the imagery and control groups, using the CLP and COP measures under the 1- and 5-week conditions. All four of these tests showed significantly $(p<.001)$ more order errors in the control conditions. Thus, the group who used the imagery technique learned the items faster, could recall more items after 1 and 5 weeks, and made fewer order errors after 1 and 5 weeks. Foux $t$ tests were also performed on the forgetting decrement from 1 to 5 weeks between the imagery and control groups, using the data in each response measure. Although the mean decrement was greater with all measures for the control group, none of these differences were significant at the .05 level. This was due to the rather small loss in retention for the TLR and CR measures and a high variance associated with the CLP and COP measures.

The difference in mean learning times between groups. raises the question of the equality of the degree of learning between the two conditions. This problem is inherent in any forgetting study of this type and cannot be answered in an absolute fashion. However, it seems reasonable to assume that if learning time and degree of retrieval correlate only in a small trivial fashion within each condition, then there is no reason to believe that an average time difference between groups will create any bias in one group in terms of degree of learning. Accordingly, correlation coefficients were performed between learning times and retrieval measures after 5 weeks, where the scores were spread sufficiently, except for the recognition measure, in order to avoid a distortion of the correlation coefficient through a restriction of range. The correlations for the experimental group between learning time and the retrieval measures of CLP, TLR, and CR were $.24, .20$, and .29. For the control group they were $.08, .13$, and .36 . All correlations were not significantly different from zero at the .05 level, and all were quite small in terms of percent of variance explained. Thus, it appears that the method used during original learning was satisfactory in terms of equating original learning. Further, whatever small bias may have occurred would work against the imagery group, so conclusions regarding the superiority of the imagery group can be regarded as conservative.

Table 2 shows the number of omission and intrusion errors that occurred in the total response measure. There was no significant difference between the imagery and control groups in the proportion of intrusion errors at the 1 -week recall, 
but the proportion of intrusion errors was significantly greater for the imagery group at the 5-week recall $(p<.001)$. These data indicate a difference in retrieval processes between the two conditions. Failures in recall in the control group were basically omissions. This also occurred at the 1-week recall for the imagery group, but at the 5 -week recall the proportion of intrusion errors and omission errors was about the same for the imagery group. Further, the type of intrusion errors in the imagery group was similar to the semantic errors reported by Brown \& McNeill (1966). Of the 16 intrusion errors that occurred at the 5-week recall in the imagery condition, 9 were classified as related to the correct word on a semantic basis by two judges, for example, "dollar-money" and "troop-army." Only one of nine errors at the 5-week recall showed this relationship in the control group. DISCUSSION

The present experiment shows that the method of loci facilitates the accessibility and the ordering of high image-evoking items in comparison to the control group. Although there was no significant difference in the number of items available between groups, as measured with the recognition memory test, the ceiling effect, created by the extremely high recognition of items in both groups, prevents a firm conclusion with regard to the question of imagery techniques making traces available over longer time periods than conventional techniques.

There appears to be two reasonable explanations for the difference in the accessibility of items between the two learning techniques. The first is simply that learning concrete words by forming compound images with prior learned cue images or "conceptual pegs," as Paivio (1969) calls them, is very efficient in terms of encoding and decoding. Another possibility is that the imposition of learning by order in both conditions placed a more serious constraint on the control group. The particular arrangement of response words should be of little importance with the method of loci, since the words are being learned in relation to their cue images, not in relation to each other. The control group, however, basically learned the words by grouping them together. In this situation the words themselves had to serve as cues for the recall of further words. However, the imposition of order in learning the words prevented the Ss from forming the type of subjective categories which has been shown to be a very effective method of recalling large numbers of words (Mandler, 1967) and left them with groups of words to recall, most of
Table 2

Type of Errors in Total List Recall After 1 and 5 Weeks

\begin{tabular}{lccccc}
\hline & \multicolumn{2}{c}{$\begin{array}{c}1 \text {-Week } \\
\text { Recall }\end{array}$} & & \multicolumn{2}{c}{$\begin{array}{c}\text { 5-Week } \\
\text { Recall }\end{array}$} \\
\cline { 5 - 6 } Condition & $\begin{array}{c}\text { Intru- } \\
\text { sions }\end{array}$ & $\begin{array}{c}\text { Omis- } \\
\text { sions }\end{array}$ & & $\begin{array}{c}\text { Intru- } \\
\text { sions }\end{array}$ & $\begin{array}{c}\text { Omis- } \\
\text { sions }\end{array}$ \\
\hline Imagery & 4 & 23 & & 16 & 19 \\
Control & 8 & 115 & 9 & 169 \\
\hline
\end{tabular}

which probably were not meaningfully interrelated. The effect of this may have been to leave the control Ss with no efficiert means to search for all the items which were still in store, as shown by the recognition memory task.

\section{REFERENCES}

BROWN, R., \& MCNEILL, D. The "tip of the tongue" phenomenon. Journal of Verbal Learning \& Verbal Behavior. $1966,5,325-337$.

HART, J. T. Memory and the feeling-of tinowing experience. Journal of Educational Psychology, 1965, 56, 208-216.

MANDLER, G. Organization and memory. In K. W. Spence and J. T. Spence (Eds.),
The psychology of learning and motivation. Vol. 1. New York: Academic Press, 1967.

MILLER, G. A., GALANTER, E.. \& PRIBRAM, K. Plans and the structure of behavior. New York: Holt, Rinehart, \& Winston, 1960.

ORNE, M. T. On the social psychology of the psychological experiment: With particular reference to demand characteristics and their implications. American Psychologist, 1962, 17, 776-783.

PAIVIO, A. Mental imagery in associative learning and memory. Psychological Review, 1969, 76, 241-263.

PAIVIO, A., YUUILLE, J. C., \& MADIGAN, S. A. Concreteness, imagexy, and meaningfulness values for 925 nouns. Journal of Experimental Psychology Monograph Supplement, 1968, 76(1), Part 2.

SHEPARD, R. N. Recognition memory for words, sentences, and pictures. Journal of Verbal Learning \& Verbal Behavior, $1967,6,156-163$.

STANDING, L., CONEZIO, J., \& HABER, R. N. Perception and memory for pictures: Single-trial learning of 2500 visual stimuli. Psychonomic Science. 1970, 19, 23-24.

YATES, F. A. The art of memory. Chicago: The University of Chicago Press, 1966.

\title{
Clustering in free recall following verbal-discrimination learning*
}

\author{
JOHN H. MUELLER, EUGENE M. JABLONSKI \\ University of Missouri, Columbia, Mo. 65201 \\ and \\ FRANK E. FULKERSON \\ Western Illinois University, Macomb, Ill. 61455
}

Clustering in free recall following verbal-discrimination learning was assessed for two possible classifications: pairs vs right-wrong functions. There was considerable pairwise clustering in free recall in two different studies. This outcome does not follow directly from frequency theory or other explanations of verbal-discrimination learning which assume acquired equivalence by function; it may, however, indicate the effect of an intrapair association on the subsequent free recall organization.

The verbal-discrimination (VD) task typically presents the $S$ with several pairs of items, and the S's task is to learn to recognize which member of each pair is correct. A recent

*This investigation was supported by $B$ iomedical Sciences Support Grant FR-07053 from the General Research Support Branch, Division of Research Resources, Bureau of Health Professions Education and Manpower Training, National Institutes of Health. explanation of how VD learning occurs has assumed that the subjective frequency of experience for each member of each pair eventually becomes different (Ekstrand, Wallace, \& Underwood, 1966). Frequency theory assumes that the $S$ 's rehearsal of the $R$ terms (right terms) during feedback eventually provides the $S$ with a cue to distinguish the $R$ terms from $W$ terms (wrong terms). Since the $R$ terms will have been more frequently experienced due to 